University of Nebraska - Lincoln

DigitalCommons@University of Nebraska - Lincoln

Phylogenetic diversity of $\mathrm{Fe}(\mathrm{III})$-reducing microorganisms in rice paddy soil: Enrichment cultures with different short-chain fatty acids as electron donors

\author{
Huijuan Li \\ Chinese Academy of Sciences, Xiamen, hjli@iue.ac.cn \\ Jingjing Peng \\ Chinese Academy of Sciences, Xiamen \\ Karrie A. Weber \\ University of Nebraska-Lincoln, kweber@unl.edu \\ Yongguan Zhu \\ Chinese Academy of Sciences, Xiamen, ygzhu@rcees.ac.cn
}

Follow this and additional works at: https://digitalcommons.unl.edu/bioscifacpub

Part of the Life Sciences Commons

Li, Huijuan; Peng, Jingjing; Weber, Karrie A.; and Zhu, Yongguan, "Phylogenetic diversity of Fe(III)-reducing microorganisms in rice paddy soil: Enrichment cultures with different short-chain fatty acids as electron donors" (2011). Faculty Publications in the Biological Sciences. 199.

https://digitalcommons.unl.edu/bioscifacpub/199

This Article is brought to you for free and open access by the Papers in the Biological Sciences at DigitalCommons@University of Nebraska - Lincoln. It has been accepted for inclusion in Faculty Publications in the Biological Sciences by an authorized administrator of DigitalCommons@University of Nebraska - Lincoln. 


\title{
Phylogenetic diversity of Fe(III)-reducing microorganisms in rice paddy soil: Enrichment cultures with different short-chain fatty acids as electron donors
}

\author{
Huijuan Li, ${ }^{1,2}$ Jingjing Peng, ${ }^{1,2}$ Karrie A. Weber, ${ }^{3}$ and Yongguan Zhu ${ }^{1}$ \\ 1. Key Laboratory of Urban Environment and Health, Institute of Urban Environment, Chinese Academy of Sciences, \\ Xiamen, 361021, People's Republic of China \\ 2. Graduate University of the Chinese Academy of Sciences, Beijing, 100049, People's Republic of China \\ 3. School of Biological Sciences, University of Nebraska-Lincoln, Lincoln, NE 68588, USA
}

Corresponding authors - Huijuan Li, email hjli@iue.ac.cn ; Yongguan Zhu, email ygzhu@rcees.ac.cn

\begin{abstract}
Purpose - Microbial ferric iron reduction is an important biogeochemical process in nonsulfidogenic anoxic environments, yet the structure of microbial communities involved is poorly understood because of the lack of a functional gene marker. Here, with ferrihydrite as the iron source, we characterized the potential Fe(III)-reducing bacteria from the paddy soil in the presence of different short-chain fatty acids, formate, acetate, propionate, pyruvate, succinate, and citrate.

Materials and methods - Enrichment culture was used to characterize the potential Fe(III)-reducing bacteria in the present study. Clone library and terminal restriction fragment length polymorphism (T-RFLP) analyses of bacterial 16S rRNA gene sequence fragments were conducted to reveal the bacterial community structure.

Results and discussion - T-RFLP and cloning/sequence analysis showed that Firmicutes were the predominant phylotype in all the enrichment cultures (more than $81 \%$ of total peak height, more than $75 \%$ of all clones), whereas Geobacter spp. represented a small fraction of the bacterial community. Specifically, distinct bacterial families in the phylum Firmicutes were enriched depending on the short-chain fatty acid amended. Clostridium spp. were the predominant microorganisms in pyruvate treatment, while both Bacillus and Clostridium were enriched in formate, acetate, and propionate treatments. Sequences related to Veillonellaceae and Alkaliphilus were predominant in succinate and citrate treatment, respectively.

Conclusions - The results indicated Fe(III)-reducing microorganisms in rice paddy soil are phylogenetically diverse. Besides the well-known Geobacter species, Firmicutes-related Fe(III)-reducing bacteria might also be an important group of $\mathrm{Fe}(\mathrm{III})$ reducers in paddy soil. To confirm the populations which play an important role in situ, further studies with culture-independent mRNA-based analysis are needed.
\end{abstract}

Keywords: Enrichment culture, Fe(III)-reducing bacteria, Paddy soil, Terminal restriction fragment length polymorphism (T-RFLP)

\section{Introduction}

Rice is a staple food for more than $50 \%$ of the world's populations - http://beta.irri.org/index.php . In Asia, nearly $140,000,000$ ha are cultivated paddy soils in 2008 - http://beta.irri.org/solutions - account- ing for more than $90 \%$ of global rice production http://irri.org/about-rice . However, heavy metals such as arsenic are significant pollutants in the paddy soils within South Asia (Dittmar et al. 2010). This can greatly influence human health because rice is particularly susceptible to arsenic (As) accumulation and that 
food consumption is a primary source through which humans are exposed to arsenic contamination (Zhu et al. 2008). Anaerobic iron reduction, which can result in the release of heavy metals, including arsenic (Islam et al. 2004), may play a key role in As accumulation in rice.

Microbially mediated rather than chemical iron reduction plays a significant role in the iron redox cycling in nonsulfidogenic anoxic environments. Ferric iron can be reduced through respiratory (ferric iron as the electron acceptor) as well as fermentation (ferric iron as the electron sink) by $\mathrm{Fe}(\mathrm{III})$-reducing bacteria. Dissimilatory (respiratory) Fe(III) reduction has been established to be an important biogeochemical process in many freshwater and marine sediments for its contribution to the oxidation of both natural and contaminant organic carbon, as well as its influences on the fate of heavy metals and radionuclides (Lovley et al. 1994; Borch et al. 2010). A wide diversity of iron-reducing bacteria have been isolated, characterized, and identified from anoxic environments (see Lovley et al. 2004 for review). However, these studies have mainly been investigated in sediments and groundwater. Unlike naturally saturated sediments and wetland soils, paddy soils, especially in Asia, experience regular specific management practices, including submergence and drainage. Organic manuring such as animal manure, rice straw, and other crop residues is another management practice (Kögel-Knabner et al. 2010). These amendments introduce a significant amount of organic matter and can drive iron reduction in these environments.

Acetate is a terminal fermentation product in the degradation of complex organic matter. Thus, it is commonly used as the electron donor in experiments for enrichment and isolation of $\mathrm{Fe}(\mathrm{III})$-reducing bacteria. However, plant-derived organic matter is decomposed to glucose, lactate, monoaromatic compounds, and longchain fatty acids as well as acetate. Besides further degradation via fermentation, these forms of organic carbon also serve as electron donors and in some cases are completely mineralized to $\mathrm{CO}_{2}$ by $\mathrm{Fe}(\mathrm{III})$-reducing microorganisms (Chaudhuri and Lovley 2003; Lovley et al. 2004). Consequently, the carbon which have the potential to drive $\mathrm{Fe}(\mathrm{III})$ reduction could be the complex organic matter deposited within soils and sediments.

In paddy soils, acetate, formate, and propionate are the primary short-chain fatty acids produced during residue decomposition (Krylova et al. 1997; Yao and Conrad 2001; Rui et al. 2009; He et al. 2010). Citrate and succinate are exuded from rice roots (Aulakh et al. 2001; Hoffland et al. 2006). Therefore, in this study, we chose acetate, formate, propionate as well as succinate and citrate as the electron donor for Fe(III)-reducing microorganism enrichment cultures. Pyruvate was also chosen because it is a key intersection in the network of metabolic pathways.

The lack of a universal functional gene marker makes it still rather difficult to track the Fe(III)-reducing bacteria in the environment, thus, enrichment cultures were used in this study to identify their diversity in paddy soil. Given the physiological diversity of Fe(III)-reducing microorganisms, we hypothesize that distinct members of Fe(III)-reducing microbial community would be enriched with different organic carbon amendments.

\section{Materials and methods}

\subsection{Soil sampling}

Soil samples (top $\sim 20 \mathrm{~cm}$ ) were collected in 2009 from a submerged paddy field located in Lengshuijiang, China. Soils samples were stored in polyvinylchloride bottles, submerged in water, and then transported back to the laboratory. The soil had a $\mathrm{pH} 6.7( \pm 0.2)$, organic $\mathrm{C}$ of $29.2 \mathrm{~g} \mathrm{~kg}^{-1}( \pm 0.2)$, and total Fe of $22.3 \mathrm{~g} \mathrm{~kg}^{-1}( \pm 0.9)$ as measured by the standard methods ( $\mathrm{Lu} \mathrm{1999).}$

\subsection{Enrichment conditions}

Enrichment cultures were conducted in 50-ml anaerobic serum bottles sealed with thick butyl rubber stoppers and aluminum caps in triplicate. Piperazine- $\mathrm{N}, \mathrm{N}^{\prime}-$ bis(2-ethanesulfonic acid) (PIPES)-buffered freshwater culture medium $(10 \mathrm{mM}, \mathrm{pH}$ 6.8) containing $22 \mathrm{mM}$ of synthetic amorphous ferrihydrite $(\mathrm{FeOOH}), 0.11 \mathrm{mM}$ $\mathrm{MgCl}_{2}, 0.61 \mathrm{mM} \mathrm{CaCl}_{2}, 2 \mathrm{mM} \mathrm{NaHCO}{ }_{3}, 0.5 \mathrm{mM} \mathrm{NH}_{4} \mathrm{Cl}$, $0.05 \mathrm{mM} \mathrm{KH}_{2} \mathrm{PO}_{4}$, and vitamin and trace element solutions (Lovley 2000) was prepared, autoclaved, and cooled to room temperature under an anoxic atmosphere of $\mathrm{N}_{2}$ (99.999\% purity). Synthetic $\mathrm{FeOOH}$ was prepared using $\mathrm{FeCl}_{3}$ and $\mathrm{NaOH}$ as described previously (Schwertmann and Cornell 1996) and identified by X-ray diffraction (data not shown). Six different organic carbon substrates, formate, acetate, propionate, pyruvate, succinate, and citrate, were added to various treatments from sterile, anoxic stock solutions (final concentration, $25 \mathrm{mM}$ ). The enrichment was initiated by adding sediment slurry $(1 \mathrm{ml})$ to sterile PIPES-buffered medium $(9 \mathrm{ml})$ with resazurin as the redox indicator under a stream of $\mathrm{N}_{2}(99.999 \%$ purity). The sediment slurry was prepared by adding $10 \mathrm{~g}$ of paddy soil into $90 \mathrm{ml}$ of $0.1 \%$ sodium pyrophosphate solution and vigorous shaking for $30 \mathrm{~min}$. In addition to the experimental treatments, a control was amended with sterile, anoxic deionized water instead of organic carbon substrates. The cultures were incubated statically in the dark at $30^{\circ} \mathrm{C}$ for 24 days. 


\subsection{Chemical analysis}

Samples were periodically collected from triplicate cultures. Prior to sampling, the culture medium was homogenized by vigorously shaking for $10 \mathrm{~s}$. Liquid samples $(200 \mu \mathrm{L})$ were taken using sterile syringes and a $100-\mu \mathrm{L}$ aliquot was immediately added to a micro-centrifuge tube containing $1.5 \mathrm{ml} 0.5 \mathrm{~N} \mathrm{HCl}$ for Fe(II) analysis. After $15 \mathrm{~min}$, the extracts were centrifuged (12, $000 \times g$ ) and $100 \mu \mathrm{L}$ was added to phenanthroline in HEPES buffer according to a method modified from $\mathrm{Lu}$ (1999). Fe(II) was measured after $30 \mathrm{~min}$. The reduction of $\mathrm{Fe}(\mathrm{III})$ was measured as the accumulation of Fe(II) in $0.5 \mathrm{~N} \mathrm{HCl}$ extracts. The solution of $\mathrm{HCl}(0.5 \mathrm{~N})$ is considered to be an effective dissolving agent for most biogenic solid phase $\mathrm{Fe}(\mathrm{II})$, including magnetite (Fredrickson et al. 1998; Weber et al. 2001). Therefore, we consider the measurement of $0.5 \mathrm{~N} \mathrm{HCl}$ extractable $\mathrm{Fe}(\mathrm{II})$ to be an indicator of the production of Fe(II). The other $100 \mu \mathrm{L}$ aliquot was centrifuged and filtered through a $0.22-\mu \mathrm{m}$ nylon filter, then stored at $-20^{\circ} \mathrm{C}$ for analysis of shortchain fatty acids by ion chromatography (IonPac ${ }^{\circledR}$ AS11 analytical column, Dionex ICS-3000 system, Dionex, Sunnyvale, CA).

\subsection{DNA extraction}

Samples for DNA extraction were collected when iron reduction ceased as indicated by a plateau in Fe(II) accumulation. Collected samples as well as inoculums which were stored at $-20^{\circ} \mathrm{C}$ were centrifuged at 16,000 $\times g$ for $3 \mathrm{~min}$. The pellet was resuspended in a sterilized solution of ammonium oxalate $(200 \mathrm{mM})$ and oxalic acid $(120 \mathrm{mM})$ and incubated in the dark (about $2 \mathrm{~h}$ ) to dissolve the solid iron oxides. After all the iron oxides were dissolved, the mixture was centrifuged at 16,000 $\times g$ for $10 \mathrm{~min}$. In order to eliminate the influence of ammonium oxalate and oxalic acid, the pellet was washed with DNA extraction buffer prior to extraction. Total genomic DNA was extracted from the pellet using a CTAB (hexadecyltrimethyl ammonium bromide) protocol as previously described (Su et al. 2007).

\subsection{Terminal restriction fragment length polymorphism (T-RFLP) fingerprinting}

PCR amplification and T-RFLP analyses of bacterial 16S rRNA gene sequence fragments were conducted as described previously (Rui et al. 2009). In brief, PCR amplification was performed using primers $27 \mathrm{f}$ and $1492 \mathrm{r}$ (Lane 1991). The $5^{\prime}$ end of the forward primer was labeled with 6-carboxyfluorescein (FAM). A touchdown PCR protocol was used with an initial denaturation $\left(4 \mathrm{~min}, 94^{\circ} \mathrm{C}\right), 10$ cycles of denaturation $\left(45 \mathrm{~s}, 94^{\circ} \mathrm{C}\right)$, annealing $\left(30 \mathrm{~s}, 60-0.5^{\circ} \mathrm{C}\right)$, elongation $\left(60 \mathrm{~s}, 72^{\circ} \mathrm{C}\right)$, followed by another 22 cycles of denaturation $\left(60 \mathrm{~s}, 94^{\circ} \mathrm{C}\right)$, annealing $\left(60 \mathrm{~s}, 55^{\circ} \mathrm{C}\right)$, elongation $\left(60 \mathrm{~s}, 72^{\circ} \mathrm{C}\right)$, and a final elongation of $72^{\circ} \mathrm{C}$ for $10 \mathrm{~min}$. The FAM-labeled PCR products were purified using an agarose gel DNA extraction kit (TaKaRa \#DV805A) and digested at $37^{\circ} \mathrm{C}$ for $5 \mathrm{~h}$ by Msp I (TaKaRa \#D1053A). Fifty microliter of $100 \%$ ethanol and $2.5 \mu \mathrm{L} 3 \mathrm{M}$ sodium acetate ( $\mathrm{pH} 5.2)$ were added to the digestion products and stored at $-20^{\circ} \mathrm{C}$ overnight. DNA precipitate was collected by centrifugation at 18 , $000 \times g$ for $30 \mathrm{~min}$. The products were then washed using $70 \%$ ethanol and centrifuged at $18,000 \times g$ for $15 \mathrm{~min}$. Finally, the purified products were air-dried and then were size-separated using the 3130xl Genetic Analyzer (Applied Biosystems).

\subsection{Cloning, sequencing, and phylogenic analysis}

Clone libraries were constructed from bacterial 165 rRNA gene sequences recovered from cultures and the soil as inoculum. The primers for PCR amplification were the same as those indicated above but without a label. Products (equal concentrations) from three replicates PCR amplification were combined, purified (Ta$\mathrm{KaRa}$ \#DV805A), and ligated into the pMD 19-T vector (TaKaRa \#D102A) according to the manufacturer's instructions. Plasmids were transformed into Escherichia coli JM 109 cells (BioTeKe \#DP7502), and clones were randomly selected and checked for correct insert size via standard-targeted PCR and agarose gel electrophoresis. Sequencing was performed with an ABI 3730xl sequencer using BigDye terminator cycle sequence chemistry (Applied Biosystem).

Sequences were phylogenetically identified using RDP-II Classifier and Sequence Match (Cole et al. 2005) in combination with NCBI BLASTN search program. The closest relatives to the clone sequences were aligned with Molecular Evolutionary Genetics Analysis 4.0 software for phylogenetic analyses (Tamura et al. 2007). Phylogenetic trees were constructed using the neighborjoining method. Robustness of derived groupings was tested by bootstrap using 1,000 replications.

\subsection{Nucleotide sequence accession number}

Nucleotide sequences generated in this study were submitted to GenBank under the following accession numbers FR668304 to FR668397.

\section{Results}

\section{1 $\mathrm{Fe}(\mathrm{III})$ reduction and short-chain fatty acids oxidation}

The rate and extent of $\mathrm{Fe}(\mathrm{III})$ reductions were variable between different treatments (Figure 1). Three trends of 

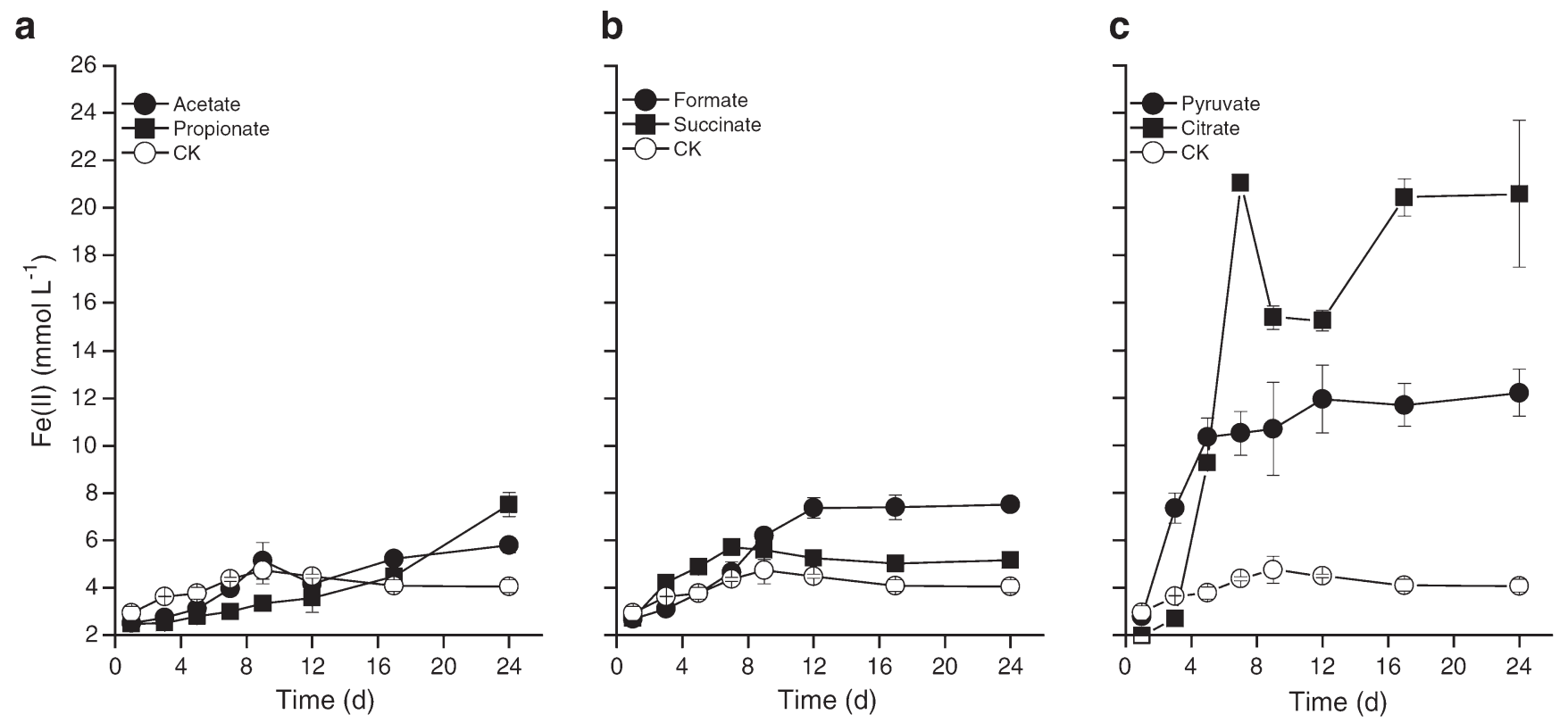

Figure 1. Fe(III) reduction in anaerobic enrichment cultures with different short-chain fatty acids (a, b, c). Data are means of triplicates; error bars indicate means $\pm \mathrm{SE}$

Fe(III)-reducing dynamics could be distinguished for all the treatments. In acetate and propionate treatments, $\mathrm{Fe}(\mathrm{III})$ reduction was comparatively slow, with an average rate of 308 and $264 \mu \mathrm{mol} \mathrm{L}^{-1} \mathrm{~d}^{-1}$ for the first 17 days of incubation, respectively (Figure 1a). Finally, about $26 \%$ of the Fe(III) added in acetate treatment and $34 \%$ in propionate treatment were reduced at the end of incubation. $\mathrm{Fe}(\mathrm{III})$ reduction in formate $\left(615 \mu \mathrm{mol} \mathrm{L}^{-1} \mathrm{~d}^{-1}\right)$ and succinate $\left(814 \mu \mathrm{mol} \mathrm{L}^{-1} \mathrm{~d}^{-1}\right)$ treatments were a little rapid than that in treatments amended with acetate and propionate followed by a plateau after 12 and 7 days of incubation, respectively (Figure 1b). However, the extent of Fe(III) reduced in the formate $(34 \%)$ and succinate $(25 \%)$ treatments was comparable to those in propionate and acetate treatments, respectively. Rapid and extensive reduction was observed in pyruvate and citrate treatments (Figure 1c). Forty-eight percent of the Fe(III) added was reduced within 5 days $\left(2,068 \mu \mathrm{mol} \mathrm{L}^{-1} \mathrm{~d}^{-1}\right)$ when pyruvate was amended, while in citrate treatment, approximately all $(94 \%)$ was reduced within 7 days $\left(3,006 \mu \mathrm{mol} \mathrm{L}^{-1} \mathrm{~d}^{-1}\right)$. $\mathrm{Fe}(\mathrm{III})$ reduction was also observed in control, resulting in the accumulation of $4.74 \mathrm{mM} \mathrm{Fe}(\mathrm{II})$ and $25 \%$ of the Fe(III) was added.

Organic carbon consumption was monitored throughout the experiment. The concentration of formate decreased slightly throughout the experiment, while the decrease of acetate and propionate was undetectable (Figure 2a-c). Pyruvate rapidly decreased to detection limit in 3 days (Figure $2 \mathrm{~d}$ ), resulting in the accumulation of acetate $(20 \mathrm{mM})$. Similarly, succinate and citrate were depleted within 5 and 7 days, concomitant with the increase of propionate and acetate, respectively (Figure 2e, f).
According to theoretical stoichiometry (Lovley 1995), $\mathrm{CH}_{2} \mathrm{O}_{2}+2 \mathrm{Fe}(\mathrm{III})+\mathrm{H}_{2} \mathrm{O} \rightarrow \mathrm{HCO}_{3}^{-}+2 \mathrm{Fe}(\mathrm{II})+2 \mathrm{H}^{+}$ $\mathrm{C}_{2} \mathrm{H}_{4} \mathrm{O}_{2}+8 \mathrm{Fe}(\mathrm{III})+4 \mathrm{H}_{2} \mathrm{O} \rightarrow 2 \mathrm{HCO}_{3}{ }^{-}+8 \mathrm{Fe}(\mathrm{II})+9 \mathrm{H}^{+}$ $\mathrm{C}_{3} \mathrm{H}_{6} \mathrm{O}_{2}+14 \mathrm{Fe}(\mathrm{II})+7 \mathrm{H}_{2} \mathrm{O} \rightarrow 3 \mathrm{HCO}_{3}{ }^{-}+14 \mathrm{Fe}(\mathrm{II})+16 \mathrm{H}^{+}$

$\mathrm{Fe}(\mathrm{III})$ reduction in the present study would only couple with the oxidation of 37,7 , and $5 \mu \mathrm{mol}$ of formate, acetate, and propionate, respectively. This is in agreement with slight decrease of formate and undetectable loss of acetate and propionate. Though not followed over the course of the experiment, inorganic carbon was also a likely product in pyruvate, succinate, and citrate treatments. Accordingly, electrons produced and used for iron reduction was calculated from the concentration of organic matter at the end of incubation (Table 1). The total quantity of electrons produced was compared to that used to reduce Fe(III). Obviously, only $5-10 \%$ of electrons in the associated organic matter was transferred to Fe(III) oxides.

\subsection{Composition of bacterial populations}

Eight clone libraries of bacterial $16 \mathrm{~S}$ rRNA genes were constructed to determine the composition of bacterial community during enrichment culture as well as the paddy soil used as inoculum (Table 2 and Supplementary Material, Resource 1). The paddy soil inoculums were primarily composed of members within the Proteobacteria (up to 57\%). However, after 24 days of incubation, members of the Firmicutes were predominant microbial community in all the enrichment cultures. These members represented more than $75 \%$ of all clones 
Figure 2. Dynamics of shortchain fatty acids in enrichment cultures with different short-chain fatty acids (a) formate, (b) acetate, (c) propionate, (d) pyruvate, (e) succinate, and (f) citrate. Data are means of triplicates except (a) because some data were missed; error bars indicate means $\pm \mathrm{SE}$

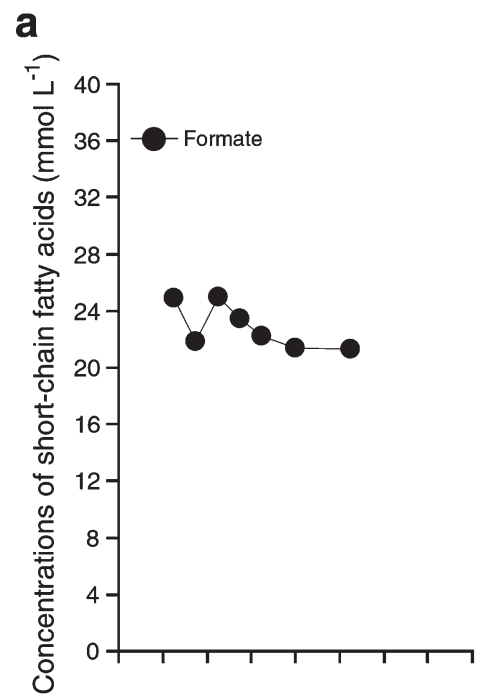

b

C

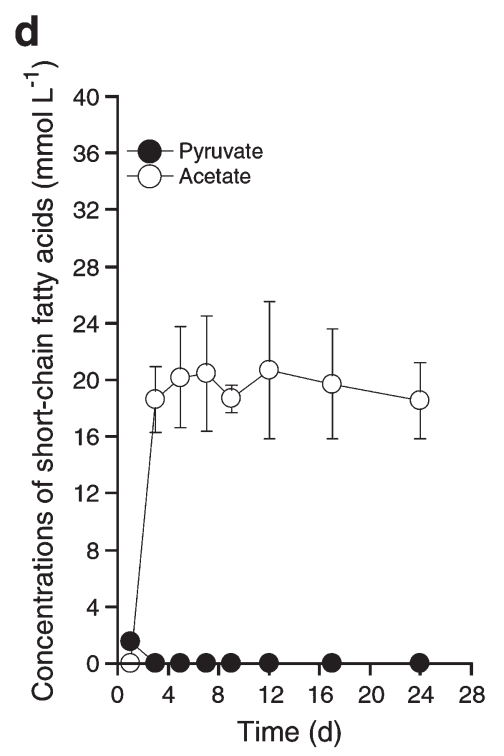

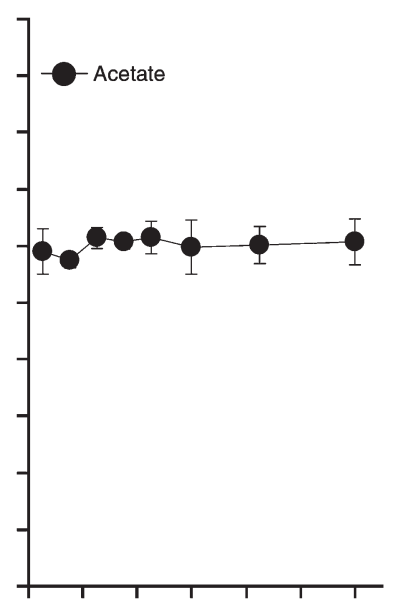

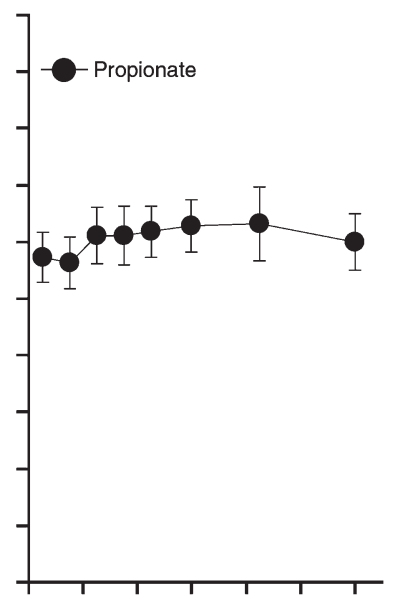

e

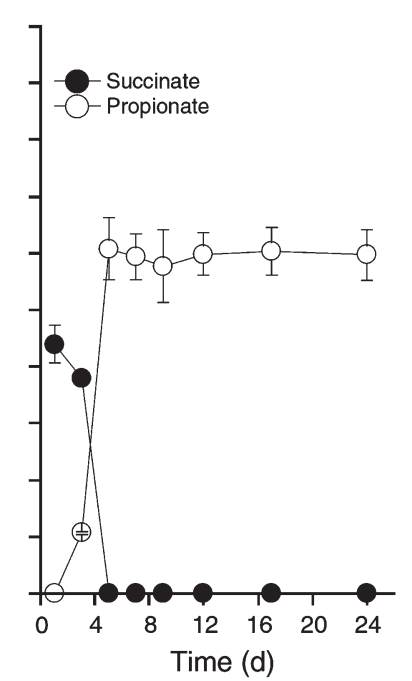

f

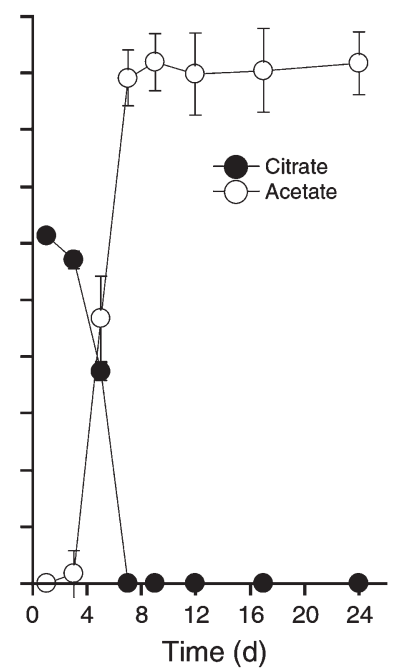

and even as high as $98 \%$ in pyruvate, succinate, and citrate treatments.

Table 1. Metabolic values measured and calculated after 24 days of enrichment incubation amended with pyruvate, succinate, and citrate

\begin{tabular}{lrrr}
\hline & Pyruvate & Succinate & Citrate \\
\hline Fe(II) $(\mu \mathrm{mol})$ & 120 & 50 & 200 \\
Pyruvate/succinate/citrate $(\mu \mathrm{mol})$ & 250 & 250 & 250 \\
$\mathrm{C}_{2} \mathrm{H}_{4} \mathrm{O}_{2} / \mathrm{C}_{3} \mathrm{H}_{6} \mathrm{O}_{2}(\mu \mathrm{mol})$ & 200 & 240 & 360 \\
${\text { Inorganic carbon }(\mu \mathrm{mol})^{\mathrm{a}}}_{\text {Electron production }\left(\mathrm{meq} \mathrm{e}^{-}\right)}$ & 1,190 & 280 & 780 \\
Percentage of electron implicated in & 10 & 980 & 2,340 \\
$\quad$ the Fe(III) reduction $(\%)$ & & 5 & 9 \\
\end{tabular}

a. Inorganic carbon contents were estimated stoichiometrially, the carbon incorporated into bacterial biomass was also included.

\subsection{T-RFLP fingerprinting of the bacterial community}

The bacterial community was analyzed by T-RFLP in combination with sequences of a clone library constructed from bacterial 16S rRNA genes. Following Rui et al. (2009), only those with a relative abundance higher than $5 \%$ in at least one profile were selected as the signature T-RFs for analyses of bacterial community. A combination of in silico analyses of 630 sequences and the T-RFLP fingerprinting of the representative clones were used to assign the major T-RFs to individual bacterial lineages (Table 3). T-RFLP profiles revealed that short-chain fatty acids substantially influenced the structure of Fe(III)-reducing bacterial community. The T-RFs of 139, 149, 268, and 508 bp were abundant in formate, acetate, and propionate treatments (Figure 3a-c). The 159-bp T-RF was also present in formate and acetate treatments. Obviously, T-RFLP profiles in pyruvate, 
Table 2. Phylogenetic affiliation and percentage of clone numbers of bacterial 16S rRNA genes retrieved from enrichment cultures amended with different short-chain fatty acids and the control (CK) after 24 days incubation, and the paddy soil used as inoculum (CS)

\begin{tabular}{|c|c|c|c|c|c|c|c|c|}
\hline \multirow[t]{2}{*}{ Affiliation } & \multicolumn{8}{|c|}{ Number/percentage (\%) } \\
\hline & Formate & Acetate & Propionate & Pyruvate & Succinate & Citrate & $\mathrm{CK}$ & CS \\
\hline \multicolumn{9}{|l|}{ Proteobacteria } \\
\hline$\beta$-Proteobacteria & $3 / 5.2$ & $3 / 3.2$ & $0 / 0$ & $0 / 0$ & $0 / 0$ & $0 / 0$ & $3 / 3.4$ & $21 / 24.1$ \\
\hline$\gamma$-Proteobacteria & $0 / 0$ & $0 / 0$ & $1 / 1.3$ & $0 / 0$ & $0 / 0$ & $0 / 0$ & $0 / 0$ & $4 / 4.6$ \\
\hline \multicolumn{9}{|l|}{ Firmicutes } \\
\hline Bacillales & $14 / 24.1$ & $31 / 33.0$ & $25 / 31.3$ & $1 / 1.4$ & $5 / 6.0$ & $11 / 16.9$ & $15 / 17.0$ & $1 / 1.1$ \\
\hline Clostridiales & $34 / 58.6$ & $49 / 52.1$ & $49 / 61.3$ & $72 / 97.3$ & $78 / 92.9$ & $53 / 81.5$ & $51 / 58.0$ & $8 / 9.2$ \\
\hline Diverse & 7/12.1 & $6 / 6.3$ & $2 / 2.5$ & $0 / 0$ & $1 / 1.2$ & $1 / 1.5$ & $13 / 14.8$ & $28 / 32.2$ \\
\hline Total number of clones & 58 & 94 & 80 & 74 & 84 & 65 & 88 & 87 \\
\hline
\end{tabular}

CK control, CS inoculum

succinate and citrate treatments differed greatly from those in formate, acetate, and propionate treatments (Figure 3d-f). The 508-bp T-RF showed a high abundance in the treatment supplemented with pyruvate (up to $57 \%$ of total peak height), while in the succinate treatment, the T-RFs of 290 and $403 \mathrm{bp}$ were present predominantly ( $43 \%$ and $57 \%$, respectively). For the citrate treatment, the T-RF with a size of $571 \mathrm{bp}$ became exclusively dominant $(50 \%)$. Seven major T-RFs were detected in control, among which the T-RF of $116 \mathrm{bp}$ was dominant (39\%) (Figure 3g). In contrast to all these enrichment incubations, the paddy soil used as inoculum was characterized by the 430-bp T-RF, which accounted for $46 \%$ of total peak height (Figure $3 h$ ).

\section{Discussion}

\subsection{Fe(III) reduction and short-chain fatty acids metabolism}

Our results showed that the amendments of carbon substrates substantially influenced the rate and extent of $\mathrm{Fe}(\mathrm{III})$ reduction. In treatments amended with citrate, $\mathrm{Fe}(\mathrm{III})$ reduction was rapid and complete $(94 \%)$, which was in line with the result when Fe(III)-citrate was used as the electron acceptor (Lovley and Phillips 1988; Wang et al. 2009). Citrate is known to mediate the dissolution of iron oxides and form Fe-citrate complexes, thus, the aqueous complexes that have formed would be available for iron-reducing bacteria. Fe(III) was also reduced rapidly when pyruvate was amended. Complexes with 1:1 ratio of $\mathrm{Fe}(\mathrm{III})$ to pyruvate were identified (Kim et al. 1972); therefore, ferrihydrite might also be dissolved by pyruvate and readily used by $\mathrm{Fe}(\mathrm{III})$ reducers in the present study.
The reduction of $\mathrm{Fe}(\mathrm{III})$ was much slower and less extensive in other treatments, which could be caused by the inability to form Fe complexes and dissolution of amorphous FeOOH. Fe(III) reduction was also observed in control. This could be due to the high content of organic carbon $\left(29.2 \mathrm{~g} \mathrm{~kg}^{-1}\right)$ in the inoculum which could be utilized as the substrate. However, it is hard to determine if it was respiratory Fe(III) reduction since the exact substrate was unknown.

Based on the close agreement between the theoretical and actual organic carbon consumed, respiratory Fe(III)

Table 3. Assignment of dominant T-RFs to defined bacterial taxa

\begin{tabular}{ll}
\hline T-RF (bp) & Affiliation \\
\hline 116 & Symbiobacterium (Incertae sedis XVIII) \\
139 & Bacillus \\
149 & Bacillaceae/Clostridiaceae \\
159 & Geobacter \\
164 & Peptococcaceae \\
268 & Clostridium \\
278 & Acidobacteria (Gp 10) \\
287 & Acidobacteria (Gp 6) \\
290 & Veillonellaceae \\
306 & Gracilibacteraceae \\
403 & Veillonellaceae \\
431 & B-Proteobacteria \\
472 & Clostridium \\
508 & Clostridium \\
515 & Clostridium \\
571 & Alkaliphilus \\
\end{tabular}


Figure 3. T-RFLP analysis of bacterial 16S rRNA genes derived from the enrichment cultures with different short-chain fatty acids after 24 days of incubation: (a) formate, (b) acetate, (c) propionate, (d) pyruvate, (e) succinate, (f) citrate, (g) the control, and (h) CS, the paddy soil used as inoculum. Data are means \pm standard error $(n=3)$. Only major T-RFs are shown

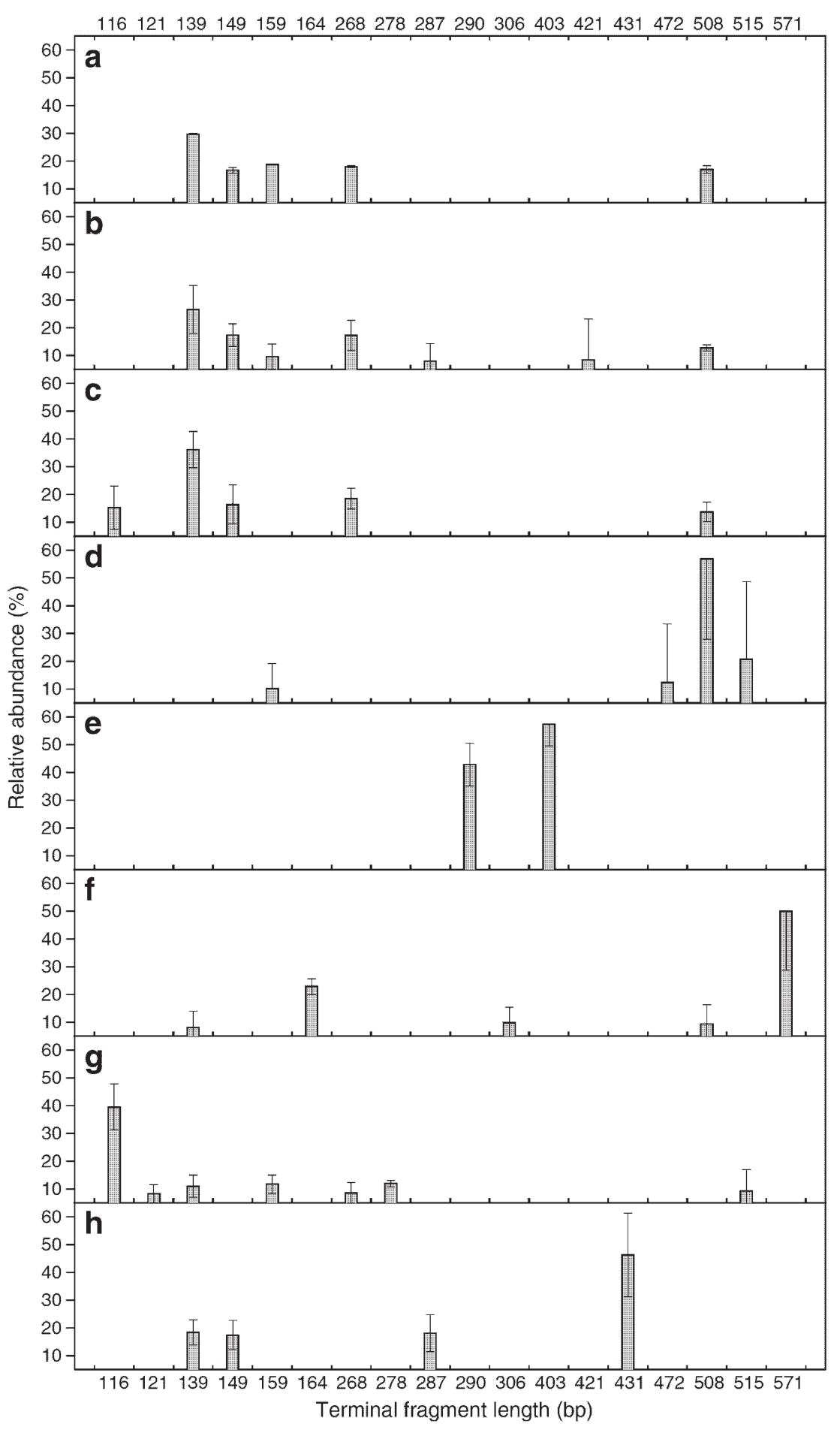

reduction was presumed to have occurred in formate, acetate, and propionate treatments. In pyruvate, succinate, and citrate treatments, since only $5-10 \%$ of electrons in the associated organic matter was transferred to Fe(III) oxides, Fe(III) served as an the electron sink rather than electron acceptor. Thus, fermentative Fe(III) reduction likely occurred in pyruvate, succinate, and citrate treatments.

\subsection{Community structure in the iron-reducing enrichments}

Iron(III)-reducing microorganisms are phylogentically and physiologically diverse, thus identification of the responsible microorganisms in situ is essential. In subsurface environments where Fe(III) reduction is an important biogeochemical process, Geobacteraceae has often 
been demonstrated to be the most abundant microorganism (Lovley et al. 2004). Recently, a study reported that Geobacter spp. accounted for about $85 \%$ of the iron-reducing communtiy in an Italian paddy soil with acetate as the electron donor and ferrihydrite as the electron acceptor (Hori et al. 2010). However, in the present study, Geobacter was only detected in control and the formate and acetate treatments, representing a minor fraction $(12 \%, 10 \%$, and $19 \%$ of total peak height, respectively). Cloning/sequence and T-RFLP analysis of the bacterial communities revealed that Firmicutes was the dominant group of Fe(III)-reducers in all the enrichment cultures. Nevertheless, it is not surprising the dominant capability of Firmicutes to reduce Fe(III), since similar results have been reported recently (Kostka et al. 2002; Scala et al. 2006; Lin et al. 2007; Boonchayaanant et al. 2009).

Specifically, the amendment of different carbon substrates selected for distinct members in the phylum of Firmicutes. Clostridium spp. were the predominant microorganisms in the culture amendment with pyruvate, while both Bacillus and Clostridium were enriched in the formate, acetate and propionate treatments. The capability of Bacillus and Clostridium to reduce Fe(III) has been reported as early as 1950-70 s (Bromfield 1954; Hammann and Ottow 1974), and further confirmed by the isolation of pure cultures in recent years. For example, Bacillus spp. have been shown to be capable of respiratory as well as fermentative Fe(III) reduction (Boone et al. 1995; Pollock et al. 2007). Clostridium had always been considered to reduce $\mathrm{Fe}$ (III) through fermentation (Dobbin et al. 1999; Park et al. 2001; Scala et al. 2006; Lin et al. 2007), however, respiratory Fe(III) reduction is also possible. A strain of Clostridium butyricum isolated from a Chinese paddy soil has showed the capability to reduce Fe(III) when glucose as well as the non-fermentative substrate (acetate) was amended (Guan 2007). In the present study, the abundant Clostridium in formate, acetate and propionate treatments also indicated the potential respiratory $\mathrm{Fe}(\mathrm{III})$ reduction by Clostridium.

Sequences related to Veillonellaceae and Alkaliphilus were predominant in succinate and citrate treatments, respectively. Clones within the cluster of Veillonellaceae shared most similarity to Sporotalea propionica, which was a propionigenic Firmicute; however, its capability to reduce Fe(III) has not been reported (Boga et al. 2007). Though the capability of Alkaliphilus species to reduce $\mathrm{Fe}(\mathrm{III})$ has been confirmed by the isolation of pure cultures (Ye et al. 2004; Lin et al. 2007), Fe(III) reduction fermentative by Alkaliphilus has not been reported.

Incertae sedis XVIII-related sequences which showed a relationship to Symbiobacterium were enriched in control. The potential for Symbiobacterium to be involved in nitrate respiration has been proven (Rhee et al. 2002; Ueda et al. 2004), however, Symbiobacterium species have so far not been directly linked to Fe(III)-reducing activity. The distinct community structure between the control and the treatments indicated that other organic carbons rather than those chosen as electron donors/ substrates in the present study was used by the Fe(III) reducers in control, which suggests that the potential electron donors/substrates for Fe(III) reducers is more complicated in paddy soils in situ.

Conclusively, Fe(III)-reducing bacteria in paddy soil are phylogenetically diverse. Besides the well-known Geobacter species, Firmicutes-related Fe(III)-reducing bacteria were also enriched in the present study. The short-chain fatty acids supplemented greatly influenced the community structure of $\mathrm{Fe}(\mathrm{III})$-reducing bacteria in the enrichment. Though Firmicutes-related Fe(III)-reducing bacteria in the present enrichment cultures were relatively abundant, it does not mean the same will be true for natural environment. To confirm the populations which play an important role in situ, further studies with culture-independent mRNA-based analysis are needed.

Acknowledgments - We thank Max M. Häggblom for discussion and critical reading of the manuscript. This study was financially supported by the Natural Science Foundation of China (Grant no. 41090282).

Supplementary material follows the References.

\section{References}

Aulakh MS, Wassmann R, Bueno C, Kreuzwieser J, Rennenberg $\mathrm{H}$ (2001) Characterization of root exudates at different growth stages of ten rice (Oryza sativa L.) cultivars. Plant Biol 3:139-148

Boga HI, Ji R, Ludwig W, Brune A (2007) Sporotalea propionica gen. nov sp nov., a hydrogen-oxidizing, oxygen-reducing, propionigenic Firmicute from the intestinal tract of a soilfeeding termite. Arch Microbiol 187:15-27

Boonchayaanant B, Nayak D, Du X, Criddle CS (2009) Uranium reduction and resistance to reoxidation under ironreducing and sulfate-reducing conditions. Water Res 43:4652-4664

Boone DR, Liu YT, Zhao ZJ, Balkwill DL, Drake GR, Stevens TO, Aldrich HC (1995) Bacillus infernus sp. nov, an Fe(III)reducing and $\mathrm{Mn}(\mathrm{IV})$-reducing anaerobe from the deep terrestrial subsurface. Int J Syst Bacteriol 45:441-448

Borch T, Kretzschmar R, Kappler A, Van Cappellen P, GinderVogel M, Voegelin A, Campbell K (2010) Biogeochemical redox processes and their impact on contaminant dynamics. Environ Sci Technol 44:15-23

Bromfield SM (1954) Reduction of ferric compounds by soil bacteria. J Gen Microbiol 11:1-6

Chaudhuri SK, Lovley DR (2003) Electricity generation by direct oxidation of glucose in mediatorless microbial fuel cells. Nat Biotechnol 21:1229-1232

Cole JR, Chai B, Farris RJ, Wang Q, Kulam SA, McGarrell DM, Garrity GM, Tiedje JM (2005) The Ribosomal Database Project (RDP-II): sequences and tools for high-throughput rRNA analysis. Nucleic Acids Res 33:D294-D296 
Dittmar J, Voegelin A, Roberts LC, Hug SJ, Saha GC, Ali MA, Badruzzaman ABM, Kretzschmar R (2010) Arsenic accumulation in a paddy field in Bangladesh: seasonal dynamics and trends over a three-year monitoring period. Environ Sci Technol 44:2925-2931

Dobbin PS, Carter JP, San Juan CGS, von Hobe M, Powell AK, Richardson DJ (1999) Dissimilatory Fe(III) reduction by Clostridium beijerinckii isolated from freshwater sediment using Fe(III) maltol enrichment. FEMS Microbiol Lett 176:131-138

Fredrickson JK, Zachara JM, Kennedy DW, Dong HL, Onstott TC, Hinman NW, Li SM (1998) Biogenic iron mineralization accompanying the dissimilatory reduction of hydrous ferric oxide by a groundwater bacterium. Geochim Cosmochim Acta 62:3239-3257

Guan SY (2007) Characterization and phylogenetic analysis of ferric reducing microorganism. Dissertation, Northwest A \& F University

Hammann R, Ottow JCG (1974) Reductive dissolution of $\mathrm{Fe}_{2} \mathrm{O}_{3}$ by saccharolytic Clostridia and Bacillus polymyxa under anaerobic conditions. Z Pflanz Bodenkunde 137:108-115

He JZ, Liu XZ, Zheng Y, Shen JP, Zhang LM (2010) Dynamics of sulfate reduction and sulfate-reducing prokaryotes in anaerobic paddy soil amended with rice straw. Biol Fertil Soils 46:283-291

Hoffland E, Wei CZ, Wissuwa M (2006) Organic anion exudation by lowland rice (Oryza sativa L.) at zinc and phosphorus deficiency. Plant Soil 283:155-162

Hori T, Muller A, Igarashi Y, Conrad R, Friedrich MW (2010) Identification of iron-reducing microorganisms in anoxic rice paddy soil by ${ }^{13} \mathrm{C}$-acetate probing. ISME J 4:267-278

Islam FS, Gault AG, Boothman C, Polya DA, Charnock JM, Chatterjee D, Lloyd JR (2004) Role of metal-reducing bacteria in arsenic release from Bengal delta sediments. Nature 430:68-71

Kim JJ, Cummings TE, Cox JA (1972) Effect of pyruvate on the redox behavior of the iron (III)-(II) couple. Anal Lett 5:703-715

Kögel-Knabner I, Amelung W, Cao ZH, Fiedler S, Frenzel P, Jahn R, Kalbitz K, Kolbl A, Schloter M (2010) Biogeochemistry of paddy soils. Geoderma 157:1-14

Kostka JE, Dalton DD, Skelton H, Dollhopf S, Stucki JW (2002) Growth of iron(III)-reducing bacteria on clay minerals as the sole electron acceptor and comparison of growth yields on a variety of oxidized iron forms. Appl Environ Microbiol 68:6256-6262

Krylova NI, Janssen PH, Conrad R (1997) Turnover of propionate in methanogenic paddy soil. FEMS Microbiol Ecol 23:107-117

Lane DJ (1991) 16S/23S rRNA sequencing. In: Stackebrandt E, Goodfellow M (eds) Nucleic acid techniques in bacterial systematics. Wiley, New York, pp 115-175

Lin B, Hyacinthe C, Bonneville S, Braster M, Van Cappellen P, Roling WFM (2007) Phylogenetic and physiological diversity of dissimilatory ferric iron reducers in sediments of the polluted Scheldt estuary, Northwest Europe. Environ Microbiol 9:1956-1968

Lovley DR (1995) Microbial reduction of iron, manganese, and other metals. Adv Agron 54:175-231

Lovley DR (2000) Fe(III)- and Mn(IV)-reducing prokaryotes. Springer, New York
Lovley DR, Phillips EJP (1988) Novel mode of microbial energy metabolism: organic carbon oxidation coupled to dissimilatory reduction of iron or manganese. Appl Environ Microbiol 54:1472-1480

Lovley DR, Woodward JC, Chapelle FH (1994) Stimulated anoxic biodegradation of aromatic-hydrocarbons using Fe(III) ligands. Nature 370:128-131

Lovley DR, Holmes DE, Nevin KP (2004) Dissimilatory Fe(III) and $\mathrm{Mn}(\mathrm{IV})$ reduction. Adv Microb Physiol 49:219-286

Lu RK (1999) Analytical methods for soil and agricultural chemistry. Agricultural Science and Technology, Beijing

Park HS, Kim BH, Kim HS, Kim HJ, Kim GT, Kim M, Chang IS, Park YK, Chang HI (2001) A novel electrochemically active and $\mathrm{Fe}(\mathrm{III})$-reducing bacterium phylogenetically related to Clostridium butyricum isolated from a microbial fuel cell. Anaerobe 7:297-306

Pollock J, Weber KA, Lack J, Achenbach LA, Mormile MR, Coates JD (2007) Alkaline iron(III) reduction by a novel alkaliphilic, halotolerant, Bacillus sp isolated from salt flat sediments of Soap Lake. Appl Microbiol Biotechnol 77:927-934

Rhee SK, Jeon CO, Bae JW et al (2002) Characterization of Symbiobacterium toebii, an obligate commensal thermophile isolated from compost. Extremophiles 6:57-64

Rui JP, Peng JJ, Lu YH (2009) Succession of bacterial populations during plant residue decomposition in rice field soil. Appl Environ Microbiol 75:4879-4886

Scala DJ, Hacherl EL, Cowan R, Young LY, Kosson DS (2006) Characterization of $\mathrm{Fe}(\mathrm{III})$-reducing enrichment cultures and isolation of $\mathrm{Fe}(\mathrm{III})$-reducing bacteria from the Savannah River site, South Carolina. Res Microbiol 157:772-783

Schwertmann U, Cornell RM (1996) Iron oxides in the laboratory preparation and characteriazation. Wiley, Weinheim

Su JQ, Yang XR, Zheng TL, Hong HS (2007) An efficient method to obtain axenic cultures of Alexandrium tamarense-a PSP-producing dinoflagellate. J Microbiol Meth 69:425-430

Tamura K, Dudley J, Nei M, Kumar S (2007) MEGA4: molecular evolutionary genetics analysis (MEGA) software version 4.0. Mol Biol Evol 24:1596-1599

Ueda K, Yamashita A, Ishikawa J, Shimada M, Watsuji T, Morimura K, Ikeda H, Hattori M, Beppu T (2004) Genome sequence of Symbiobacterium thermophilum, an uncultivable bacterium that depends on microbial commensalism. Nucleic Acids Res 32:4937-4944

Wang XJ, Yang J, Chen XP, Sun GX, Zhu YG (2009) Phylogenetic diversity of dissimilatory ferric iron reducers in paddy soil of Hunan, South China. J Soils Sediments 9:568-577

Weber KA, Picardal FW, Roden EE (2001) Microbially catalyzed nitrate-dependent oxidation of biogenic solid-phase Fe(II) compounds. Environ Sci Technol 35:1644-1650

Yao H, Conrad R (2001) Thermodynamics of propionate degradation in anoxic paddy soil from different rice-growing regions. Soil Biol Biochem 33:359-364

Ye Q, Roh Y, Carroll SL, Blair B, Zhou JZ, Zhang CL, Fields MW (2004) Alkaline anaerobic respiration: isolation and characterization of a novel alkaliphilic and metal-reducing bacterium. Appl Environ Microbiol 70:5595-5602

Zhu YG, Williams PN, Meharg AA (2008) Exposure to inorganic arsenic from rice: a global health issue? Environ Pollut 154:169-171 


\section{Supplementary Material}

Resource 1. Phylogenetic trees showing the $16 \mathrm{~S}$ rRNA gene clone sequences related to Firmicutes, including Clostridia (a) and Bacilli (b), and the other phyla (c) generated from iron-reducing enrichment cultures. Different numbers indicate different treatments $(0=$ the control, $1=$ Formate, $2=$ Acetate, $3=$ Propionate, $4=$ Pyruvate, $5=$ Succinate, $6=$ Citrate, $c s=$ the paddy soil used as inoculum). The scale bar represents $1 \%$ (a and c) or $0.05 \%$ (b) sequence divergence; The T-RF sizes are indicated.

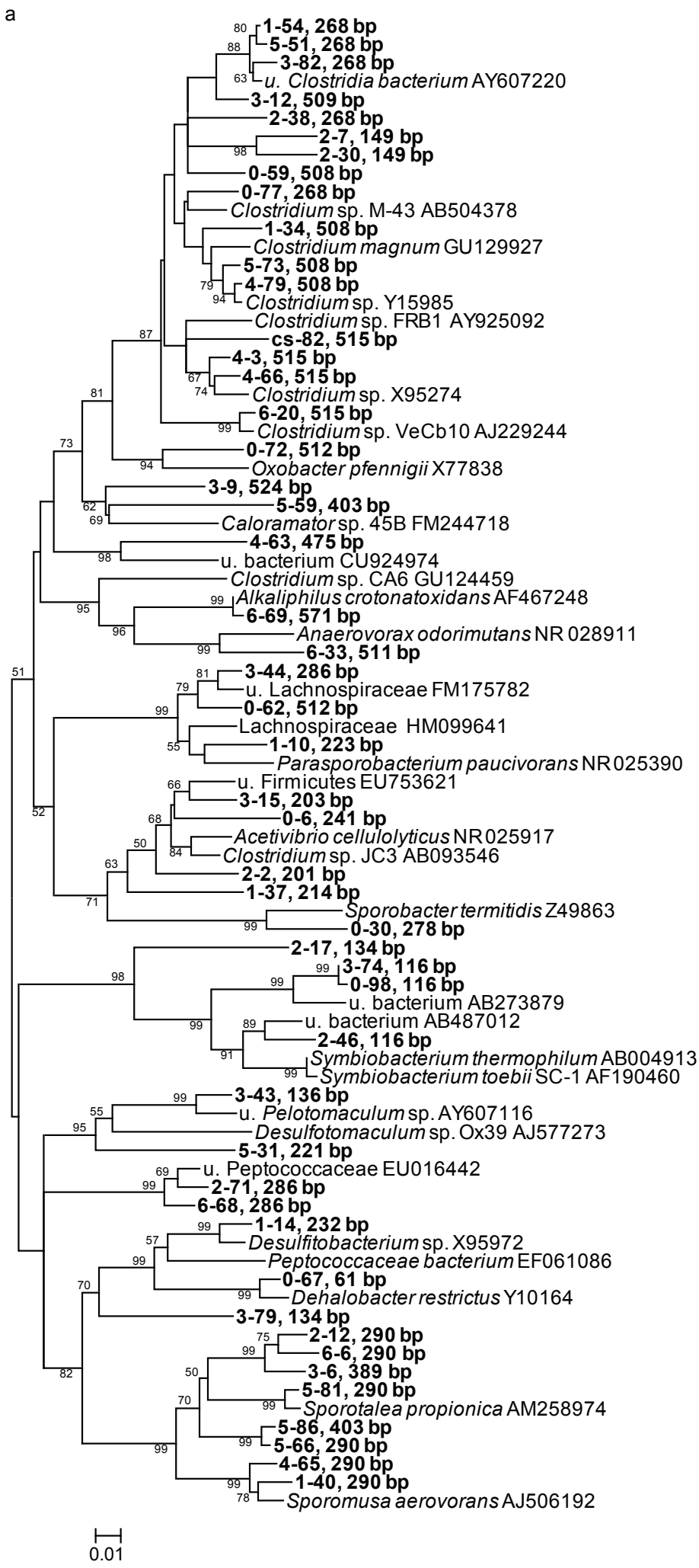

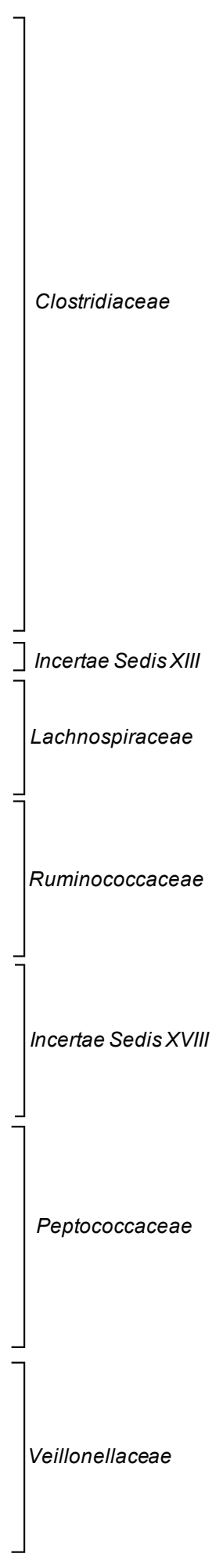




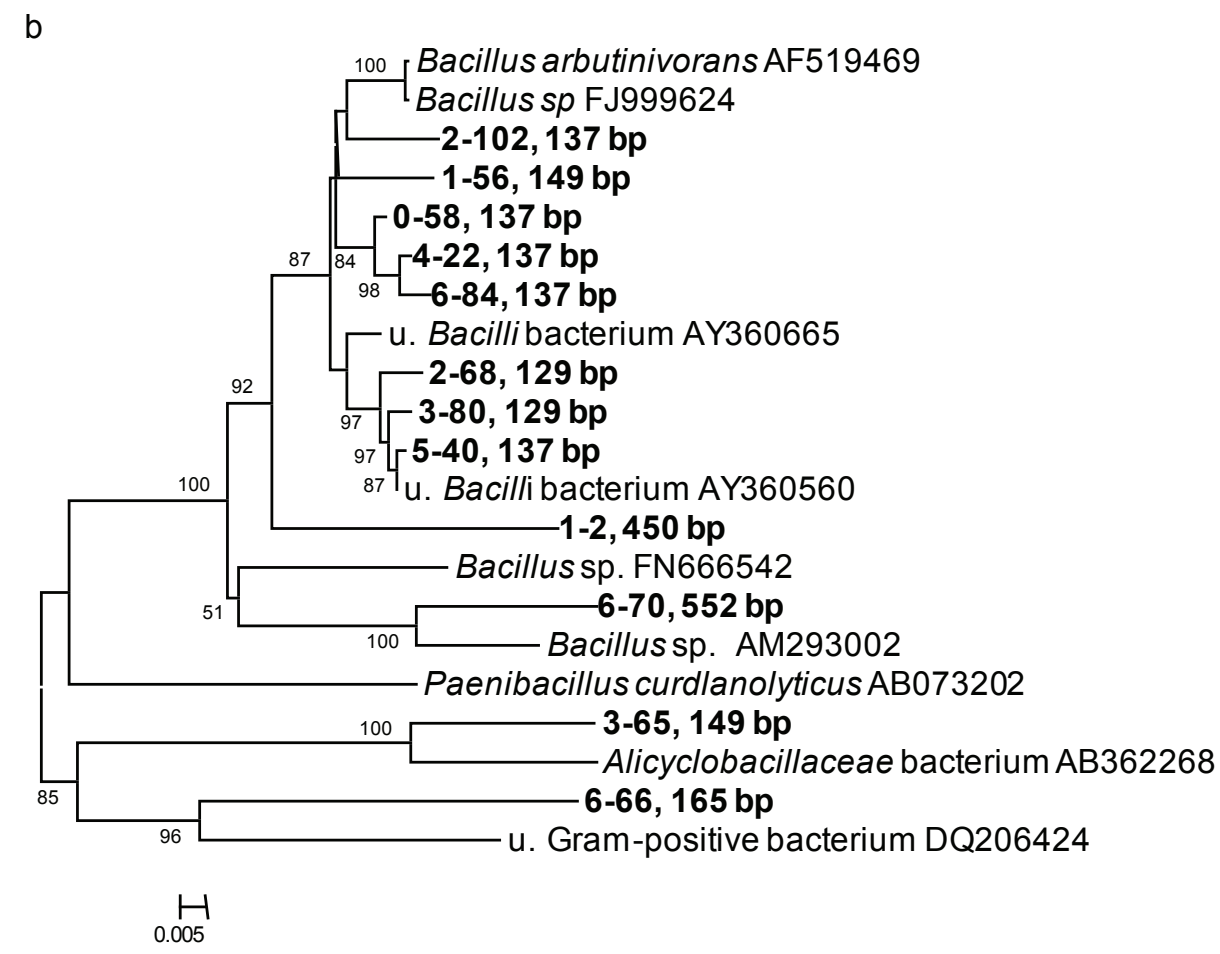


C

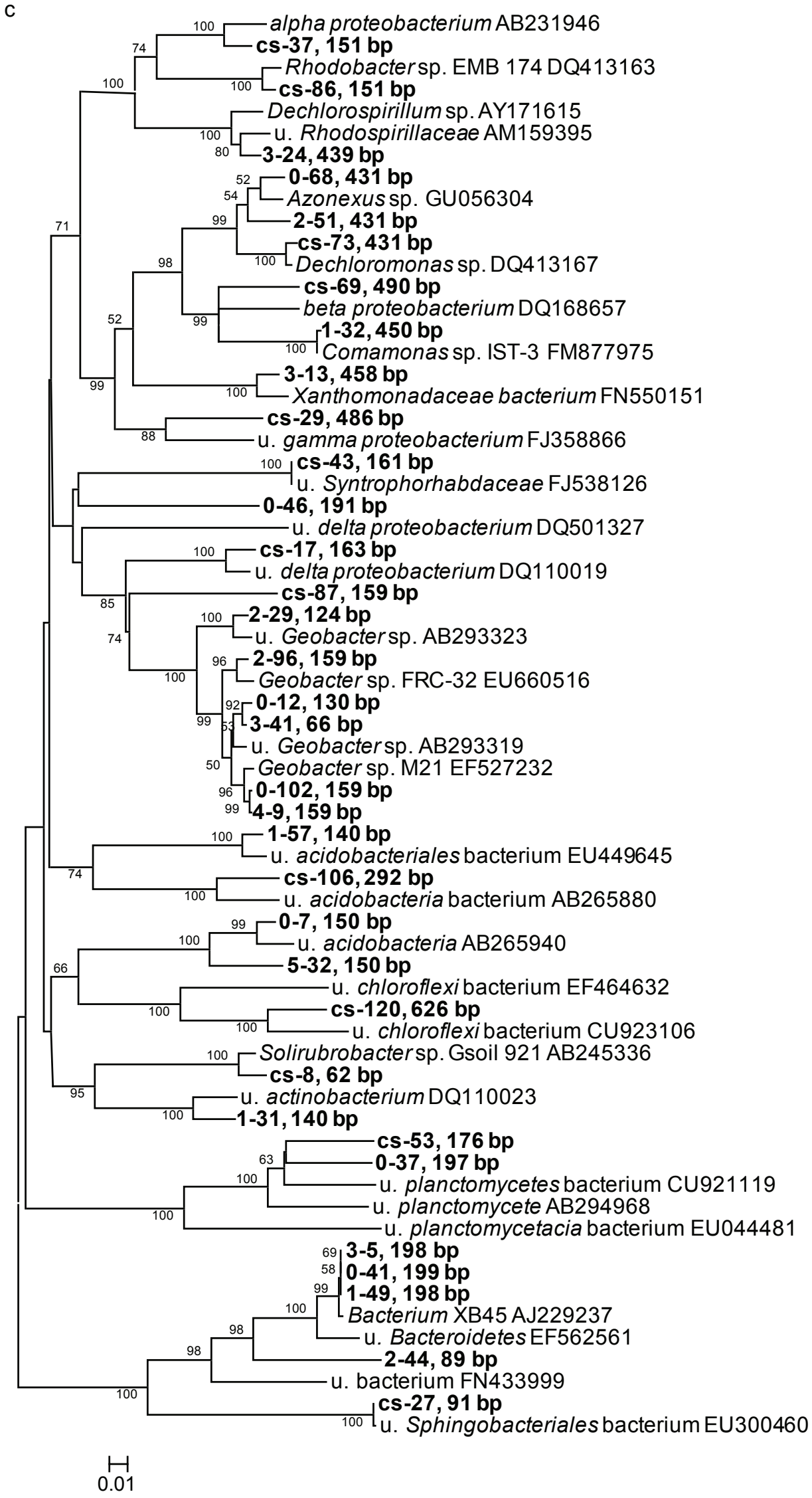

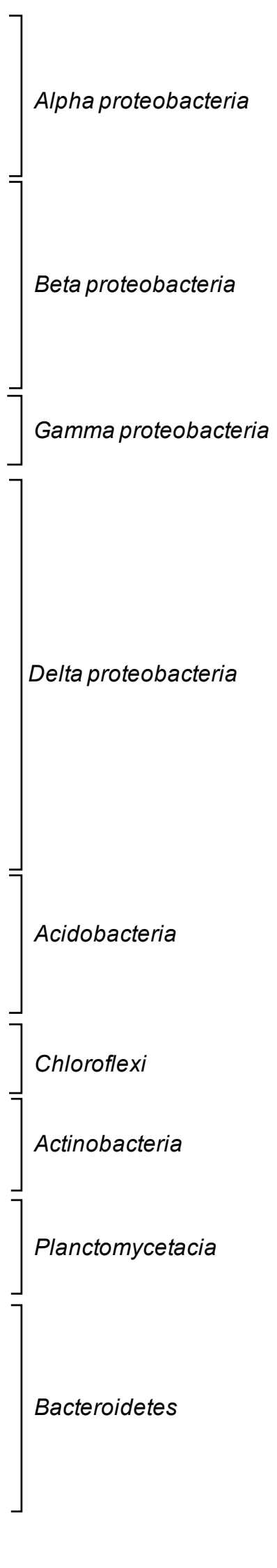

